\title{
The Relationship Between Quality of Attachment in Infancy and IQ in Kindergarten
}

\author{
MARINUS $H$. VAN IJZENDOORN \\ SITA VAN VLIET-VISSER \\ Department of Education \\ University of Leiden, The Netherlands
}

\begin{abstract}
In this study, we hypothesized that securely attached infants would in kindergarten perform better on an intelligence test than anxiously attached children. No difference was expected between children of working mothers (working more than 15 hours outside the home) and children of full-time homemakers. Mother-child pairs ( $N=77$; average age of child was 24 months) were observed during the Strange Situation procedure; three years later, 65 children completed the Leiden Diagnostic Test for measuring intelligence level. Results showed that the securely attached reference group attained the highest IQ. The working status of the mother did not appear to make a difference.
\end{abstract}

IN ATTACHMENT THEORY, quality of attachment is supposed to have some consequences for future cognitive development: Securely attached children are expected to perform better in problem-solving situations compared to anxiously attached children. In longitudinal research, securely attached children have been more active in exploring the environment at age $21 / 2(\mathrm{Ha}-$ zen \& Durrett, 1982) and at age 5 (Arend, Gove \& Sroufe, 1979). They have also been more eager to learn (Waters, Wippman, \& Sroufe, 1979) and more enthusiastic when solving problems (Matas, Arend, \& Sroufe, 1978). Bus \&

Preparation of this article was supported in part by a grant from the Nationaal Comité voor Kinderpostzegels.

We gratefully acknowledge the assistance of Miriam Lambermon in collecting data.

Requests for reprints should be sent to Marinus $H$. van IJzendoorn, Department of Education, University of Leiden, P.O. Box 9507, NL-2300 RA Leiden, The Netherlands. 
Van IJzendoorn (1985) found that the reading abilities of securely attached preschoolers were more advanced. They also appeared socio-emotionally better adapted to explore new environments and phenomena, to solve new tasks, and to overcome frustrating barriers compared to anxiously attached children. Securely attached children seem to be more ego-resilient and more optimally ego-controlled (Stroufe, Fox, \& Pancake, 1983; Van IJzendoorn \& Van Vliet-
Visser, 1986).

In this study, we hypothesized that the greater activity, enthusiasm, and emotional adaptedness of securely attached children in exploring and solving new tasks results in higher overall cognitive performance (e.g., intelligence level) compared to anxiously attached children. Children who were securely attached at 2 years of age were expected to perform better on an IQ test three years later, compared to anxiously attached children. We also hypothesized that the working status of the mother would not be related to the child's IQ because home-makers and working mothers, if their attachment relationship to the child is qualitatively comparable, should create the same conditions for cognitive development (for a review of the literature, see Goossens, 1987).

\section{Method}

\section{Subjects}

At the average age of 24 months (range: 23 to 25 months), 77 children and their mothers were tested using the Strange Situation procedure. About 50\% of the mothers were working 15 hours or more per week outside the home; the rest were full-time home-makers. Eighty-four percent $(n=65)$ of the 77 children participated in the follow-up study three years later. There were no indications that the nonparticipants were a specific subset of the original sample (Van IJzendoorn \& Van Vliet-Visser, 1986). The mean age of the children in the second stage of the study was 64 months (range: 56 to 72
months).

\section{Procedures}

Strange Situation. The videotapes of the Strange Situations were scored on four interactive scales--proximity, contact, avoidance, and resistance-during the reunion episodes (Ainsworth, Blehar, Waters, \& Wall, 1978). Intercoder reliability $(n=22)$ ranged from .77 to .97 . On the basis of these interactive scales and of descriptive notes on the other episodes, the children were classified as A, B or C group children (see Grossmann, Grossmann, Huber, \& Wartner, 1981). Agreement was $95.5 \%$; for the subcategories it was
91.5\%. The scores on these scales, and the classification, were derived from
Goossens (1987). Contrary to Vaughn Goossens (1987). Contrary to Vaughn, Deane, and Waters (1985, p. 112), 
but in accordance with Lamb, Thompson, Gardner and Charnov (1985, p. 31 ), we found the Strange Situation to be a valid procedure for 24-month-old children. Although 24-month-olds appeared to be more active on proximity seeking than younger children ( 1 to $1 \frac{1}{2}$ years old), no age differences were found on the scales for resistance and avoidance or on the classification (Goossens, Van IJzendoorn, Kroonenberg, \& Tavecchio, 1985).

Leiden Diagnostic Test. To get an indication of the level of intelligence, each child completed five subtests of the Leiden Diagnostic Test (LDT): block design, word span, repeating sentences, picture indicating, and comprehension. The LDT is a standardized IQ test for Dutch children. Reliability and validity figures can be found in Schroots (1979). Two female experimenters applied the LDT to 35 and 30 children, respectively. A two way analysis of covariance did not show significant experimenter, sex of child, or Experimenter $\times$ Sex of Child effects. The covariate socioeconomic status did have a significant effect, however.

\section{Results and Discussion}

In Table 1, the means and standard deviations of intelligence level per attachment classification are listed. The mean IQ score of the sample (111) is well above the average for the Dutch population at the same age (about 100). The socioeconomic status of the sample, however, is also above average. On an occupational index extending from unskilled labor (1) to high-level academic occupations (6), the mean socioeconomic status of the sample is 4.6 (see Van

\section{TABLE 1}

Means and Standard Deviations of IQ per Attachment Classification

\begin{tabular}{lrrr}
\hline \hline \multirow{2}{*}{$\begin{array}{l}\text { Attachment } \\
\text { classification }\end{array}$} & $n$ & \multicolumn{2}{c}{ IQ } \\
\cline { 3 - 4 } & & $M$ & $S D$ \\
\hline A1 & 2 & 108 & 13.4 \\
A2 & 8 & 110 & 11.6 \\
B1 & 18 & 108 & 12.6 \\
B2 & 10 & 112 & 12.3 \\
B3 & 9 & 120 & 13.8 \\
B4 & 14 & 107 & 12.9 \\
C1 & 2 & 118 & 3.5 \\
C2 & 2 & 114 & 4.9 \\
Total & 65 & 111 & 12.6 \\
& & &
\end{tabular}


Westerlaak, Kropman, \& Collaris, 1975). In light of this, the relatively high mean score on the intelligence test may be explained by the recruitment of
the sample from the higher socioeconomic classes.

Because some of the attachment categories are rather small, a few have been joined together to form four groups: $\mathrm{A}+\mathrm{C}, \mathrm{B} 1, \mathrm{~B} 2+\mathrm{B} 3$, and B4. The reference group comprises the $\mathrm{B} 2+\mathrm{B} 3$ group (secure children). The most negative deviation, the insecurely attached children, were placed in the A + C category. The dependently attached children were classified as B4 (Van IJzendoorn, Goossens, Kroonenberg, \& Tavecchio, 1985; Van IJzendoorn, Tavecchio, Goossens, Vergeer, \& Swaan, 1983).

To test the hypotheses about the relationship between quality of attachment, working status, and intelligence level, a $2 \times 4$ analysis of covariance was computed, with working status of the mother and attachment classification as factors and socioeconomic status as covariate. Results of the ANCOVA showed a significant regression of the covariate: $F(1,56)=12.0$, $p=.001$. The higher the socioeconomic status of the subjects, the higher their score on the LDT was. This result is comparable to the outcomes of other studies on the relationship between socioeconomic status and IQ (see Schroots, 1979). Furthermore, the attachment classification appeared to have a significant effect: $F(3,56)=3.2, p=.03$. The reference group, $\mathrm{B} 2+\mathrm{B} 3$, had the highest intelligence level. The marginal subcategories B1 and B4 showed the lowest scores on the intelligence test. The anxiously attached children in the $\mathrm{A}+\mathrm{C}$ group unexpectedly performed somewhat better than the marginal groups. The $\mathrm{C}$ group especially performed very well. An anxiously ambivalent relationship between mother and child does not appear to hamper cognitive development in the manner hypothesized. Because of the very small size of the subgroup, however, this outcome has to be replicated in other studies before interpreting it as falsifying evidence. There was no significant main or interaction effect for the working status of the mother.

Two way analyses of covariance (ANCOVAs) on the five subtests resulted in a significant main effect for attachment classification in the analysis on the subtest Comprehension, $F(3,56)=3.8, p=.016$. The securely attached reference group, B2 + B3, performed best on this verbal ability subtest. The same outcome can be reported for the ANCOVA on Word Span,
$F(3,55)=3.8, p$ covariate interaction; therefore ANCOVA showed a significant factor by made.) This subtest is also an ind correction for nonparallel slopes was attachment quality seems to be greater fon verbal ability. The influence of test than for the performance greater for the verbal aspect in the intelligence the anxiously attached children and the mrely attached children outperformed ability tasks.

The only ANCOVA with a significant main effect for working status of the mother was the analysis of Word Span: $F(1,55)=4.5, p=.039$. Chil- 
dren of working mothers had higher scores than children of full-time homemakers. This result falsifies, of course, the suggestion that inevitably detrimental effects on preschoolers' intelligence level occur if their mothers work outside the home for more than 15 hours per week.

In conclusion, the securely attached reference group, B2 + B3, appeared to attain the highest intelligence level in kindergarten, as measured by the LDT. Recently, Lamb et al. (1985, p. 156) stated that no reliable predictive association between attachment status and later cognitive competence has yet been demonstrated. Although our sample size precludes definitive conclusions, we found some evidence for the cognitive superiority of the securely attached group. Quality of attachment in the second year of life does appear to make a difference for cognitive development. The marginal groups B1 and B4 performed less well, as was expected, and they did not differ much from the anxiously attached children. Ainsworth et al. (1978) emphasized the bor derline status of B1 and B4 children, and demanded more research to give them a definitive position in the classification system. In line with earlier studies on the status of B4 children (Van IJzendoorn et al., 1983, 1985), our results indicate a substantial difference in cognitive development between dependently and securely attached children.

\section{REFERENCES}

Ainsworth, M. D. S., Blehar, M. C., Waters, E., \& Wall, S. (1978). Patterns of attachment: A psychological study of the Strange Situation. Hillsdale, NJ: Erlbaum.

Arend, R., Gove, F. L., \& Sroufe, L. A. (1979). Continuity of individual adaptation from infancy to kindergarten: A predictive study of ego-resiliency and curiosity in preschoolers. Child Development, 50, 950-959.

Bus, A. G., \& Van IJzendoorn, M. H. (1985). Attachment and early reading: A longitudinal study. Unpublished manuscript, University of Leiden/Groningen, Department of Education.

Goossens, F. A. (1987.). Maternal employment and daycare. In L. W. C. Tavecchio \& M. H. van IJzendoorn (Eds.), Attachment in social networks: Contributions to the Bowlby-Ainsworth attachment theory. Amsterdam: Elsevier (North Holland).

Goossens, F. A., Van IJzendoorn, M. H., Kroonenberg, P. M., \& Tavecchio, L. W. C. (1985). Sex and age differences in the Strange Situation. Unpublished manuscript, University of Leiden, Department of Education.

Grossmann, K. E., Grossmann, K., Huber, F., \& Wartner, U. (1981). German children's behavior towards their mothers at 12 months and their fathers at 18 months in Ainsworth's Strange Situation. International Journal of Behavioral Development, 4, 157-181.

Hazen, N., \& Durrett, M. (1982). Relationship of security of attachment to exploration and cognitive mapping in 2-year-olds. Developmental Psychology, 18, 751759.

Lamb, M. E., Thompson, R. A., Gardner, W., \& Charnov, E. L. (1985). Infantmother attachment: The origins and developmental significance of individual differences in Strange Situation behavior. Hillsdale, NJ: Erlbaum. 
Matas, L., Arend, R. A., \& Sroufe, L. A. (1978). Continuity of adaptation in the second year: The relationship between quality of attachment and later competence. Child Development, 49, 547-556.

Schroots, J. J. F. (1979). Leidse diagnostische test. Deel 5, Cognitieve ontwikkeling, leervermogen en Schoolprestaties. [Leiden Diagnostic Test. Part 5. Cognitive development and school achievement.] Lisse, The Netherlands: Swets \& Zeitlinger.

Stroufe, L. A., Fox, N. E., \& Pancake, V. R. (1983). Attachment and dependency in developmental perspective. Child Development, 54, 1615-1625.

Van IJzendoorn, M. H., \& Van Vliet-Visser, S. (1986). Gehechtheid, egoveerkracht en -controle. Een longitudinale studie. [Attachment, ego-resiliency and ego-control. A longitudinal study.] Kind en Adolescent, 7, 77-90.

Van IJzendoorn, M. H., Goossens, F. A., Kroonenberg, P. M., \& Tavecchio, L. W. C. (1985). Dependent attachment: B4 children in the Strange Situation. Psychological Reports, 57, 439-451.

Van IJzendoorn, M. H., Tavecchio, L. W. C., Goossens, F. A., Vergeer, M. M., \& Swaan, J. (1983). How B is B4? Attachment and security of Dutch children in Ainsworth's Strange Situation and at home. Psychological Reports, 52, 683-691.

Van Westerlaak, J. M., Kropman, J. A., \& Collaris, J. W. M. (1975). Beroepenklapper. [Socio-economic status manual.] Nijmegen, The Netherlands: ITS.

Vaughn, B. E., Deane, K. E., \& Waters, E. (1985). The impact of out-of-home care on child-mother attachment quality: Another look at some enduring questions. Monographs of the Society for Research in Child Development, 50 (1-2, Serial No. 209), pp. 110-135.

Waters, E., Wippman, J., \& Sroufe, L. A. (1979). Attachment, positive affect, and competence in the peer group: Two studies in construct validation. Child Development, $50,821-829$. 